\title{
Physical Therapy Rehabilitation after Traumatic Brain Injury
}

\section{Kênia Kiefer Parreiras de Menezes}

Department of Physical Therapy, Federal University of Minas Gerais, Brazil

*Corresponding author: Kênia Kiefer Parreiras de Menezes, Department of Physical Therapy, Universidade Federal de Minas Gerais, Avenida Antônio Carlos, 6627, Campus Pampulha, 31270-901 Belo Horizonte, Minas Gerais, Brasil, Tel: 55-31-3409-7403; Fax: 55-31-3409-8403; E-mail: keniakiefer@yahoo.com.br

Received date: August 25, 2015; Accepted date: August 26, 2015; Published date: August 30, 2015

Copyright: (2015 Parreiras de Menezes KK. This is an open-access article distributed under the terms of the Creative Commons Attribution License, which permits unrestricted use, distribution, and reproduction in any medium, provided the original author and source are credited.

\begin{abstract}
Traumatic Brain Injury (TBI) is an important public health problem and leading cause of injury death and disability in worldwide. The heterogeneity of this condition leads to a high degree of variety in the manifestation of clinical symptoms and makes the treatment of the accident victims particularly challenging. Because of this, the physiotherapist plays a central role in leading, coordinating and providing a continuum of care and services over the course of the patient's recovery. However, there are no major differences between the various methods of treatment and all of them improve the patients' functional status. Furthermore, evidence suggests that community integration should be the primary goal of rehabilitation for people after a TBI. However, very little is known about how variations on the individual characteristics (family support, education, quality and availability of community services, financial condition) may also influence the community integration.
\end{abstract}

Keywords: Brain injuries; Stroke; Rehabilitation

\section{Introduction}

Traumatic Brain Injury (TBI) is an important public health problem and leading cause of injury death and disability in worldwide $[1,2]$. Although rates of TBI deaths decreased in the last years, that are attributable to preventive measures and better overall treatment, the TBI incidence increased, increasing also the numbers of survivors with sequels [1]. These patients can experience long-term physical, cognitive, behavioral, and emotional consequences [2] due an extremely varied spectrum of possible lesions, resulting in many potential disabilities [3]. Furthermore, each person has a different set of premorbid abilities and a different psychosocial situation [3] that leads to a high degree of heterogeneity in the manifestation of clinical symptoms and makes the treatment of the accident victims particularly challenging [4]. Because of this, the rehabilitation process needs to be carefully planned and the goals need to be holistic, long term and individualized to each survivor and his or her family [3].

The TBI can cause long-term physical disability and the neurological impairments such as motor function (coordination, balance, walking, hand function, speech) and sensory loss are important sequels that affect the quality of life [3]. The physical therapy rehabilitation needs to identify these impairments and help the person to achieve the maximum degree of return to their previous level of functioning [3]. Thus, the physiotherapist plays a central role in leading, coordinating and providing a continuum of care and services over the course of the patient's recovery [5] and the early involvement of then as part of the acute managing is fundamental [6].

\section{Physical Rehabilitation}

The neurological consequences of TBI are numerous and complex requiring extensive and specific rehabilitation of the affected person [7]. There is strong evidence that early and intensive rehabilitation has many positive effects on patients with TBI, as a result of the plasticity of the brain and other mechanisms [7]. In this acute phase the physiotherapist more commonly focuses on respiratory care, passive range of motion treatment, and reduction of spasticity [8]. On the other hand, in the later phases, the treatment more frequently consists of functional training and training of compensator strategies, among other approaches [8].

Many different methods of assessment, treatment, and evaluation of the outcome of rehabilitation have been suggested for use by physiotherapists working with patients with TBI [7]. However, there are no major differences between the various methods of treatment and all of them improve the patients' functional status [7]. It is possible, maybe because the variety of symptoms consequences of TBI can lead to various specific treatments for each case and thus, making difficult to create a most optimal therapeutic method. Furthermore, relatively few research studies have been published in the area of TBI, once that is high the heterogeneity of the symptoms, which would also explain the paucity of high quality randomized controlled studies [9].

On the rehabilitation process, first the physiotherapist needs to identify the physical impairments, which may be directly related to the brain injury or secondary to concomitant orthopedic or spinal cord injury [5]. It is necessary to assess the injury severity and elaborate an initial functional prognostication based on acute injury variables [5]. The purpose was to get an idea about the patient's needs and capacity for progress in the rehabilitation [7]. Finally, the professional coordinate the rehabilitation therapy, considering the results of the assessment. For this, some specific physiotherapeutic methods showed positive effects on patients with TBI and can be recommended, such as mobilization, sensory stimulation, fitness or aerobic training, respiratory therapy, contracture prophylaxis and functional training (sit-to-stand, gait and arm ability training) [4,9]. These different methods for treatment are chosen for many different reasons by the physiotherapists, but the most important is to choose based on the patient's problems. Furthermore, also it is necessary to repeat the same assessments or tests as were performed before, during and after the rehabilitation and reassess whether the goals of the start of treatment were achieved [7]. 


\section{Community Rehabilitation}

The goals expressed by these patients frequently are the wish to get well again and to be able to take care of oneself [7]. After TBI, return of function is not restricted to physical reintegration but also includes reintegration in the social, emotional, community and vocational domains [5]. Evidence suggests that community integration should be the primary goal of rehabilitation for people after a TBI [10]. However, helping a person to return to maximum independence and participation in the community is an extremely difficult task and requires the dedicated involvement of the patient, treatment team and family $[3,5]$. The family support, the education, the quality and availability of community services, the financial condition and other variables interfere on this process and may limit access of the patients [3]. However, we know very little about how variations on these characteristics may also influence the community integration [10]. Driving retraining and virtual reality training could be important resources in this process [3], but more research is needed to inform best practice guidelines to meet the needs of this growing TBI population [10].

\section{Conclusion}

TBI is a heterogeneous condition in terms of etiology, severity, and outcome [11]. Despite a progressive and significant reduction in mortality and increase in the incidence, there isn't a most optimal therapeutic method for this condition. There are a few randomized controlled studies that deliver proof of efficacy for specific methods but, in most cases, they do not prove superiority in comparison with other methods so that further research is imperative. Furthermore, enhancing integration of subjects after TBI into their community of choice, with particular emphasis on social integration and quality of life, should be an important rehabilitation goal. However, few studies investigated this process for this population.

\section{References}

1. Coronado VG, Xu L, Basavaraju SV, McGuire LC, Wald MM, et al. (2011) Surveillance for traumatic brain injury-related deaths--United States, 1997-2007. MMWR Surveill Summ 60: 1-32.

2. Langlois JA, Rutland-Brown W, Wald MM (2006) The epidemiology and impact of traumatic brain injury: a brief overview. J Head Trauma Rehabil 21: 375-378.

3. Khan F, Baguley IJ, Cameron ID (2003) 4: Rehabilitation after traumatic brain injury. Med J Aust 178: 290-295.

4. Hellweg S (2012). Effectiveness of physical therapy and occupational therapy after traumatic brain injury in the intensive care unit. Crit Care Res Pract 2012: 1-7.

5. Chua KS, Ng YS, Yap SG, Bok CW (2007) A brief review of traumatic brain injury rehabilitation. Ann Acad Med Singapore 36: 31-42.

6. Horn LJ (1992). Systems of care for the person with traumatic brain injury. Phys Med Rehab Clin North Am 3: 475-493.

7. Holmberg TS, Lindmark B (2008). How do physiotherapists treat patients with traumatic brain injury? Adv iPhysiother 10: 138-145.

8. Carr J, Shepherd R (2003). Stroke rehabilitation, guidelines for exercise and training to optimize motor skill. Philadelphia: Elsevier Science.

9. Hellweg S, Johannes S (2008) Physiotherapy after traumatic brain injury: a systematic review of the literature. Brain Inj 22: 365-373.

10. Ritchie L, Wright-St Clair VA, Keogh J, Gray M (2014) Community integration after traumatic brain injury: a systematic review of the clinical implications of measurement and service provision for older adults. Arch Phys Med Rehabil 95: 163-174.

11. Dinsmore J (2013). Traumatic brain injury: an evidence-based review of management. Contin Educ Anaesth Crit Care Pain 24: 1-7. 